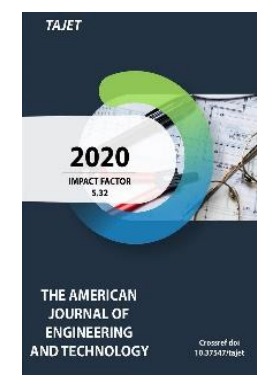

Journal Website: http://usajournalshub.c om/index,php/tajet

Copyright: Original content from this work may be used under the terms of the creative commons attributes 4.0 licence.

\section{Analysis Of Selected Fabric Properties For Children's Light Clothing}

\author{
Jamoliddin Samatovich Ergashev \\ Doctor Of Technical Sciences, Head Of The Department “Light Industry Product Design \\ Performance And Technology", Namangan Institute Of Engineering And Technology, \\ Uzbekistan
}

Dilrabo Khabibillayevna Rayimberdiyeva

Senior Lecturer, Department Of “Light Industry Product Design Performance And

Technology", Namangan Institute Of Engineering And Technology, Uzbekistan

Rashida Abduganiyevna Ergasheva

Senior Lecturer, Department Of "Light Industrial Production Development And Technology", Namangan Institute Of Engineering And Technology, Uzbekistan

Vasila Kabulovna Kenjayeva

2nd Course Master Student, Namangan Institute Of Engineering And Technology, Uzbekistan

\title{
ABSTRACT
}

This article examines the analysis of selected fabric properties for children's light clothing. Also in this article, as each garment has its own function, when choosing a material for children's shoulder garments, it is necessary to take into account its characteristics, the sum of the average values for all indicators, the characteristics of relative sensitivity, the most noticeable. After determining the feature indicators, the relative sensitivity coefficient was calculated to distinguish them from the indicators, the relative significance of the selected indicators was checked using the formula, and the concordance coefficient was determined to assess the suitability of the study.

\section{KEYWORDS}

Model, fabric, aesthetics, non-wrinkle, air permeability, impermeability, seam strength, vapor permeability, abrasion resistance, drapery;

\section{INTRODUCTION}

These days, the development of the textile and fashion industry in Uzbekistan, the growing demand

for high-quality exclusive designer products, the emergence of a generation of fabrics that open unlimited opportunities for designers, all this requires 
the production of new types of light industry products. Due to the fact that the tasks of the light industry are to fully meet the needs of the population, to provide the market with the necessary products, to expand the range of products, to increase the demand for clothing, the following research was conducted.

Clothing is a means of protecting the human body from the effects of the external environment. One of the things that makes a person beautiful is his inner and outer beauty. Each piece of clothing has its own function. Besides age, gender and working conditions, it is important to choose the right shape, model, fabric and sewing process, as well as hair, shoes, bags and accessories.

The issues of high quality products are not only technical, but also economic, social and political. Product quality is taken into account in the design of the product, ensured during the production process and is reflected in the service life. So quality can be described as a complex “system". In order to ensure quality, it is necessary to manage it at every stage of the production process. Currently, quality has become a problem not only in direct processing industries, but also in cross-industry sectors, since the quality of consumer goods is provided by hundreds of enterprises.

Product quality management means maintaining a leading level of quality in the design, production and consumption processes of the product, constantly monitoring the factors that affect it.

In practice, it is known that no clothing that a person wears is judged on its merits.. We can divide the indicators that determine the quality of clothing into operational, ergonomic and technological types.

\section{THE MAIN FINDINGS AND RESULTS}

Like all manufactured goods, clothing is "reliable," which is an important indicator of performance.. The reliability of the garment during operation is characterized by the shape, durability of the parts, the strength of the seams..

Determination of the characteristics of children's clothing.

$$
\begin{gathered}
\text { X1-Aesthetics; } \\
\text { X2- No wrinkles; } \\
\text { X3-Air permeability; } \\
\text { X4-Lack of access; } \\
\text { X5-Weld strength; } \\
\text { X6-Vapor permeability; } \\
\text { X7- Resistance to carving; } \\
\text { X8- Drapability; }
\end{gathered}
$$


Table 1

\begin{tabular}{|c|c|c|c|c|c|c|c|c|c|}
\hline expert ciphers & $\mathrm{X}_{1}$ & $\mathrm{X}_{2}$ & $\mathrm{X}_{3}$ & $\mathrm{X}_{4}$ & $\mathrm{X}_{5}$ & $\mathrm{X}_{6}$ & $\mathrm{X}_{7}$ & $\mathrm{X}_{8}$ & \\
\hline 1 & 2 & 4 & 1 & 6 & 8 & 5 & 7 & 3 & 36 \\
2 & 1 & 3 & 4 & 5 & 8 & 7 & 6 & 2 & 36 \\
3 & 8 & 5 & 2 & 3 & 7 & 4 & 6 & 1 & 36 \\
4 & 2 & 3 & 1 & 8 & 5 & 6 & 7 & 4 & 36 \\
5 & 2 & 3 & 1 & 7 & 5 & 6 & 4 & 8 & 36 \\
6 & 2 & 3 & 1 & 7 & 5 & 6 & 8 & 4 & 36 \\
7 & 1 & 2 & 3 & 7 & 6 & 8 & 4 & 5 & 36 \\
8 & 1 & 3 & 2 & 6 & 5 & 4 & 7 & 8 & 36 \\
\hline $\mathrm{S}_{\mathrm{i}}$ & 19 & 26 & 15 & 49 & 49 & 46 & 49 & 35 & 288 \\
$\mathrm{~m}^{*} \mathrm{n}-\mathrm{S}_{\mathrm{i}}$ & 45 & 38 & 49 & 15 & 15 & 18 & 15 & 29 & \\
$\mathrm{~J}_{\mathrm{i}}$ & 0.20 & 0.17 & 0.22 & 0.07 & 0.07 & 0.08 & 0.07 & 0.13 & \\
$\mathrm{~J}_{\mathrm{io}}$ & 0.19 & 0.16 & 0.2 & & & & & 0.13 & \\
$\mathrm{~S}_{\mathrm{io}}$ & 1.5 & 1.2 & 1.5 & & & & & 1 & \\
$\mathrm{~S}_{-}-\mathrm{S}_{\mathrm{i}}$ & 17 & 10 & 21 & -13 & -13 & -10 & -13 & 1 & \\
$\left(\mathrm{~S}-\mathrm{S}_{\mathrm{i}}\right)^{2}$ & 289 & 100 & 441 & 169 & 169 & 100 & 169 & 1 & 1438 \\
\hline
\end{tabular}

$$
\sum_{i=1}^{n} R j i=0,5 \times m \times(n-1)=0,5 \times 8 \times(8-1)=36
$$

Here: m-number of experts,

$\mathrm{n}$ - number of indicators.

1. Find the sum of the average scores for all indicators: 


$$
\bar{S}=\frac{1}{n} \cdot \sum_{i=1}^{n} S_{i}=0.5 \cdot m \cdot(n+1)
$$

$$
\begin{aligned}
& X_{1}=8 * 8-19=45 \\
& X_{2}=8 * 8-26=38 \\
& X_{3}=8 * 8-15=49 \\
& X_{4}=8 * 8-49=15 \\
& X_{5}=8 * 8-49=15 \\
& X_{6}=8 * 8-46=18 \\
& X_{7}=8 * 8-49=15 \\
& X_{8}=8 * 8-35=29
\end{aligned}
$$

2. Determining the properties of relative sensitivity:

$$
\begin{aligned}
& J_{i}=\frac{m \cdot n-S_{i}}{m \cdot n^{2}-m \cdot \sum_{i=1}^{n} R_{j i}} \\
& X_{1}=8 * 8-19 / 8 * 82-8 * 36=0,20 \\
& X_{2}=8 * 8-26 / 8 * 82-8 * 36=0,17 \\
& X_{3}=8 * 8-15 / 8 * 8^{2}-8 * 36=0,22 \\
& X_{4}=8 * 8-49 / 8 * 82-8 * 36=0,07 \\
& X_{5}=8 * 8-49 / 8 * 82-8 * 36=0,07 \\
& X_{6}=8 * 8-46 / 8 * 82-8 * 36=0,08 \\
& X_{7}=8 * 8-49 / 8 * 82-8 * 36=0,07 \\
& X_{8}=8 * 8-35 / 8 * 82-8 * 36=0,13
\end{aligned}
$$

3. Identify the most significant feature indicators:

$$
J_{i o} \phi \frac{1}{n} \text {; }
$$




$$
J_{\text {io }} \phi \frac{1}{n}=\frac{1}{8}=0.125
$$

To distinguish between indicators, we determine the coefficient of relative sensitivity.

$$
J_{i o}=\frac{m \cdot n-S_{i}}{m \cdot n^{2} \cdot n_{0}-S_{i}}
$$

Here: $\mathbf{n}_{\mathbf{0}}$ - the number of significant indicators:

$$
\begin{gathered}
n_{0}=4 \\
X_{1}=8 * 8-19 / 8 * 8 * 4-19=0,19 \\
X_{3}=8 * 8-26 / 8 * 8 * 4-26=0,16 \\
X_{6}=8 * 8-15 / 8 * 8 * 4-15=0,2 \\
X_{7}=8 * 8-35 / 8 * 8 * 4-35=0,13
\end{gathered}
$$

4. We determine the relative importance of the selected indicators using the following formula.

$$
S_{j o}=\frac{J_{i o}}{J_{\text {min }}}
$$

$\mathrm{J}_{\min }$ - the smallest of the significant indicators.

$$
\begin{aligned}
& J_{\min }=0,13 \text { equal } \\
& X_{1}=0,19 / 0,13=1,5 \\
& X_{3}=0,16 / 0,13=1,2 \\
& X_{6}=0,2 / 0,13=1,5 \\
& X_{7}=0,13 / 0,13=1
\end{aligned}
$$

5. Determining the concordance coefficient to assess the adequacy of the opinions of experts:

$$
X_{\text {hisob }}^{2}=W \cdot m \cdot(n+1)=0.54 \cdot 8 \cdot(8+1)=38.88
$$




$$
W=\frac{\sum_{i=1}^{n}\left(\bar{S}-S_{i}\right)^{2}}{\frac{1}{12} \cdot m^{2}\left(n^{3}-n\right)-m \sum_{i=1}^{n} T_{j}}=\frac{1438}{\frac{1}{12} \cdot 64 \cdot(512-8)-8}=\frac{1438}{2680}=0.54
$$

Table 2

\begin{tabular}{|c|c|c|c|c|c|c|c|c|c|c|}
\hline \multicolumn{10}{|c|}{ Degree of freedom (m-1)=7 } \\
\hline Probability & 1 & 2 & 3 & 4 & 5 & 6 & 7 & 8 & 9 & 10 \\
\hline 0.01 & 6.6 & 9.2 & 11.9 & 13.9 & 15.1 & 16.8 & 19.5 & 20.1 & 21.7 & 29.2 \\
\hline 0.05 & 3.8 & 6.0 & 7.8 & 9.5 & 11.1 & 12.6 & 14.1 & 15.5 & 16.9 & 19.3 \\
\hline
\end{tabular}

$\mathrm{X} 2$ table $=14.1$ so $38.88>14.1$ in the case of research

W found correct.

The purpose of clothing is to protect the human body from external influences and create a favorable microclimate for normal life. At the same time, clothing has the ability to change a person's appearance by up to $60 \%$. In the process of garment production, the material is selected for the garment directly based on the above functions. The difference between the choice of material for children's sportswear and the choice of material for other items is that it is necessary to determine the most significant characteristics of the material.

Today, as a result of the development of science, the quality of light industry products is growing. Accordingly, the structure of the material, the composition of the fiber, the weaving method is selected.

The development of the textile and chemical industries has led to an expansion of the range of materials. With the rational use of natural raw materials, new types of fibers are created that are resistant to various influences in order to replace them. At the same time, due to the nature of the product, a mixture of natural and synthetic fibers is used to produce fabrics with the appropriate parameters.

The fabric for children's light clothing is selected based on the following significant parameters:

- Aesthetics;

- Not wrinkled;

- Air permeability;

- Drapability

Aesthetics, of course, means that the look of the garment can be attractive in the first place. "Aesthetic" means the degree to which a garment is 
made of a new range of materials, the use of new add-ons, and the satisfaction of the consumer's aesthetic tastes.

If the product or product meets the aesthetic requirements, it can find a consumer in the market and become a consumer, one of the pre-market goods.

Bending and compression deformations cause the fabric to wrinkle, which means that it forms folds and creases. Wrinkles and creases can only be removed by wet ironing. The shrinkage of fabrics depends on their fiber content, the thickness of the yarn used in their structure, the type of weaving and finishing, the density. One of the disadvantages of fabrics is their Non-wrinkle. It spoils the look of the item. Folding fabrics for children's sportswear are not recommended because they wear out quickly, and bent and twisted areas are more likely to rub. Nonwrinkle means that the fabric resists wrinkling and returns to its original state after wrinkling. Nonwrinkle is determined by the direction of the material, both in the body and in the back.

Air permeability is the air permeability of a fabric, which depends on its fiber content, density and texture. Non-thick fabrics are breathable, dense fabrics are impregnated with waterproof solutions, and rubberized fabrics are completely or less permeable to air.

The draping of fabrics is said to cause them to form soft and fine folds. This feature depends on the strength and weight of the fabric. The greater the thickness of the fabric, the greater the force required to bend it, and the smaller the twist. As the mass of the fabric increases, so does its twist.

The quality of a product and its marketability depends not only on the production technology, but also on what material it is made of.

Based on all of the above, it is available in cotton lavsan fabric.

\section{CONCLUSION}

In conclusion, we can say that the choice of fabric for children's clothing has a high aesthetic value. Children's clothes should have a degree of crease, as they are fast-moving. To protect baby skin, the fabric must be hygienic. Children's clothes should retain their quality even when worn for a long time, for which the drapery plays an important role.

\section{REFERENCES}

1. Resolution of the President of the Republic of Uzbekistan dated December 21, 2016 No PP2687 "On the program of measures for further development of the textile and clothing industry in 2017-2019."

2. Maltseva E.P. Sewing materials science. Moscow: Legprombitizdat. 1986.

3. Ochilov T.A; Matmusaev U.M; Kulmetov M.K. Testing of textile materials. Tashkent: "Uzbekistan", 2004.

4. Abbasova N.G. and others. "Materials science of light industry products". Part I. Textbook. Tashkent: Aloqachi-2005.

5. Abdugaffarov A.A. Methodical manual on laboratory lessons on the subject "Textile Materials Science”. Tashkent: TTYSI, 2010. 